\title{
Perception of Health Information Management Professionals on the Importance of Computer System in Health Information Management in Obafemi Awolowo Teaching Hospital, Ile- Ife, Osun State, Nigeria
}

\author{
Ayodele Kolawole Musa ${ }^{1}$ Ogbonna Mary Aina, ${ }^{2}$ Ojo Phebean Opeyemi ${ }^{3}$ \\ ${ }^{1-2}$ Department of Health Information Management, College of Health Sciences and Technology, \\ Ijero-Ekiti. Ekiti -State, Nigeria. \\ ${ }^{3}$ Department of Computer Science, College of Health Sciences and Technology, Ijero-Ekiti. Ekiti -State, Nigeria.
}

\begin{abstract}
Healthcare system in this contemporary time is moving towards digitalization with respect to management of patients' health information, this is however pertinent to achieve improved healthcare quality, Information and Communication Technology (ICT) in hospital settings.
\end{abstract}

The process therefore requires migrating from paper records to Electronic Health Records (EHRs) particularly in Africa where it has been a lingering challenge. However, adopting technology in the management of patient records will provide more accurate and details patient's profile. This study therefore investigated perceptions of health Information Management Professionals on the importance of computer system in health information management in Obafemi Awolowo University Teaching Hospital ,Ile-Ife, Osun- State, Nigeria. A descriptive survey design was adopted and thirty (30) Health Information Management Professionals were randomly selected from Obafemi Awolowo Teaching Hospital.

The result revealed that majority of Health Information Management Professionals agree that computer science is of high importance in Health Information Management as it was seen as critically important for effective clinical documentation and patients' management care. It was recommended among others that governments at all level should provide adequate and updated facilities for hospitals to enhance effective Electronic Health Records (EHRs) with required training for Health Information Management Professionals.

Keywords:- Perception, Health Information Management, Computer Science, Professionals Importance, Osun-state.

\section{INTRODUCTION}

Health Information Technology (HIT) involves dimension of information and communication technologies that are expedient for collection, transmission, displaying and saving the patient information. [1]

Computers are one of most veritable tools with high level of accuracy, speed, updating information and presence of world wide web. The knowledge of computer science remains vital part of existence as they are being used on daily basis as exigency demands. [2]

In the past, role of computer science in hospital setting and among public health professionals were not prominent. [3]

However, in recent times, technology has been prominent and is at its peak, every field is therefore influenced by computer application and health information Management in hospital setting is therefore paying a pivotal role in efficient Patient management care. [4]

However, the role of computer science cannot be overemphasised as it is required for the formation and maintenance of patients' record important in health surveillance and also pertinent to Health Information System as it is required in explaining geographical Information system and Electronic medical records.

Computer Science is also being used in statistical analysis of various data and hence enhances health professionals to be innovative and contend with contemporary challenges. [5]

Information and communication technology (ICT) is mostly used as an extended synonym for information technology [6]. It is a more specific term that emphasizes the role of unified communications and the integration of communications. It comprises of computing technology, the Internet and other accessories which enable users to 
access, store, transmit, and manipulate information. Cruickshank [7] established that peoples' attitude towards computer and computerization becomes more favourable as their experience of computers and computer technologies increases. In line with this assertion, Fairley [8] maintained that the rapid advances in userfriendly interfaces of the computer have lessened the need to know the intricacies of how the machines work. In the same vein, the Internet is a global system of interconnected computer networks that uses the standard internet guidelines for billions of users [9]. Equally, it depicts history with the development of electronic computers in the 1950s and was first introduced to the public by the University of Califonia Los angeles [10]

It is equally worthy to know that application of Health Information Technology minimises medical errors cost and paper work. It also increases efficiency, quality of health care and empowerment of patients and clinicians [11]

However, despite all these advantages, acceptance of health Information Technology by health professionals must be of paramount. Overtime findings reveals that in most countries, acceptance of computer science among health professionals was very low as particularly observed among aging groups [12] .Hence, need to investigate into the perception of Health Care workers particularly Health Information Professionals on the importance of computer science in securing effective Electronic Health Records in health institutions as concern developing countries.

\section{AIM OF THE STUDY}

Both National and International development advocate for accessibility to Healthcare information , However, implementation of Health Information Technology (HIT) has therefore become indispensable through health care professionals particularly Health Information Management. In Nigeria few studies exist that illustrate the perception of Health Information Management professionals on the adoption of Technology. Therefore, this study will:

- assess knowledge utilization and perceptions of computer science application among Health Information Management professionals.

- provide the opportunity for healthcare organizations to improve quality of care and patient safety through effective Electronic Health records.

- provide comprehensive, reliable, relevant, accessible, and timely patient information to each member of the healthcare team

- make the information collection more efficient, readable, and more easily disseminated

- reduce human error in the documentation of patient information in Obafemi Awolowo Teaching Hospital Ile-Ife, Osun- State Nigeria.

\section{Research Questions}

In order to achieve the objectives of this study, following are research questions:

- How critical is electronic health information needed in meeting your organization goals as Health Information management Professional?

- How important is computer system to you as Health Information Management Professionals?

- How can you rate your performance in relation to Electronic Health Record as Health Information management Professional?

- What is your perception about computer application as Health Information management Professional?

- What are the barriers to the implementation Electronic Health Records in your institution (EHR )?

\section{METHODOLOGY}

The Research work was conducted at Obafemi Awolowo Teaching Hospital Ile-Ife, Osun- State Nigeria. Descriptive survey research design was adopted for the study. Data was generated from the respondents on their perception on the importance of computer science in Health Information Management. The research design is concerned with the totality of the plan used in executing a research study. It lays out the plan for investigation the research questions and details of the study which flows from the specific questions asked. [13]

Thirty (30) Health Information Management professionals were purposely selected for the study which comprised of males and females

\section{> Methods of Data Collection}

Data collected was analysed using descriptive statistics. The descriptive statistics was used to present details of the demographics using frequencies, percentages, means and standard deviations. How can you rate your performance in relation to Electronic Health Record as Health Information management Professionals

\section{Ethical Consideration}

After the participants were duly informed of the purpose and users of the study, their right to either stay or withdraw from the study and after assurances of utmost confidentiality of data to be obtained, informed consent was received from them.

\section{RESULTS}

\begin{tabular}{|c|c|c|}
\hline Age range & Frequency & percentage \\
\hline $21-30$ & 10 & $33.33 \%$ \\
\hline $31-40$ & 15 & $50 \%$ \\
\hline $41-50$ & 5 & $16.67 \%$ \\
\hline Total & 30 & $100 \%$ \\
\hline
\end{tabular}

Table 1:- Age Range of the Respondents 
ISSN No:-2456-2165

Table 1 shows $33.3 \%$ of the respondents are between the ages of 21-30years, $50 \%$ of the respondents are between the ages of $31-40$ while $16.67 \%$ respondents are between 41-50 years. It shows that higher percentages of the respondents are in their active working group which may enhance their suitability to adapt to computer application.

\begin{tabular}{|c|c|c|}
\hline SEX & Frequency & Percentage \\
\hline Male & 25 & $83.33 \%$ \\
\hline Female & 5 & $16.67 \%$ \\
\hline Total & 30 & 100 \\
\hline
\end{tabular}

Table 2:- Gender Distribution of the Respondents

Table 2 shows the distribution of the respondents by gender, $83.3 \%$ of the respondents are male while $16.67 \%$ are female, it shows that male are far more than the females among the respondents.

\begin{tabular}{|c|c|c|c|c|c|c|}
\hline Item & Critically important & Important & Neutral & Low important & Not important & Total \\
\hline Clinical quality & $10(33.33 \%)$ & $5(16.67) \%$ & $3(10 \%)$ & $2(6.67 \%)$ & $5(16.67 \%)$ & $30(100 \%)$ \\
\hline Patience service & $15(50) \%$ & $4(13,33) \%$ & $1(3.33 \%)$ & $6(20 \%)$ & $4(13.33 \%)$ & $30(100 \%)$ \\
\hline Operation service & $8(26.67 \%)$ & $8(26.67 \%)$ & $4(13.33)$ & $2(6.67 \%)$ & $8(26.67 \%)$ & $30(100 \%)$ \\
\hline
\end{tabular}

Table 3:- Respondents' answer on how critical is electronic health information needed in meeting your organization goals as Health Information management Professional?

In table above, majority of the respondents opined that electronic health information is critically important in meeting organisation goals. $33.33 \%$ opine is critically important in clinical quality, 50\% agree is critically needed in patience service while $26.67 \%$ agree is critically important in operation service.

\begin{tabular}{|c|c|c|}
\hline Level of importance & Respondent & Percentage \\
\hline Not important & 6 & $20 \%$ \\
\hline Very Important & 24 & $80 \%$ \\
\hline Total & 30 & $100 \%$ \\
\hline
\end{tabular}

Table 4:- shows respondents on how important is computer system in Health Information Management

The table above reveals the perception of the respondents on how important computer science in Health Information Management, higher percentage of the respondents (80\%) opined that computer application very important while only $20 \%$ of the respondents stated that computer system is not important in Health Information Management.

\begin{tabular}{|c|c|c|}
\hline Performance & Respondent & Percentage \\
\hline Low & 6 & $20 \%$ \\
\hline High & 24 & $80 \%$ \\
\hline Total & 30 & $100 \%$ \\
\hline
\end{tabular}

Table 5:- Respondents rating their performance in relation to Electronic Health Record as Health Information management Professional.

In table above, respondents rated their performances in relation to Electronic Health Record (HER), it shows that majority of the respondents $(80 \%)$ rated their performances high which depicts that most of the Health Information management Professional are already adapted to computer application in Obafemi Awolowo Teaching Hospital Ile-Ife, Osun- State Nigeria.

\begin{tabular}{|c|c|c|}
\hline Acceptance of EHR & Respondent & Percentage \\
\hline Easy & 10 & $33.33 \%$ \\
\hline Difficult & 5 & $16.67 \%$ \\
\hline Satisfying & 10 & $33.33 \%$ \\
\hline frustrating & 5 & $16.67 \%$ \\
\hline
\end{tabular}

Table 6:- Respondents' perception about computer application as Health Information Management Professional

Table above reveal respondents' perception about computer application as Health Information Management Professional, $33.33 \%$ of the respondents perceived that computer application is easy and equally satisfying respectively however, $16.67 \%$ opined that computer application is difficult and frustrating equally. It can be deduced that majority of the Health Information Management Professionals are adapted to Electronic Health Records at Obafemi Awolowo Teaching Hospital Ile-Ife, OsunState Nigeria. 
ISSN No:-2456-2165

\begin{tabular}{|c|c|c|c|c|}
\hline & Not a barrier & Minor barrier & Major barrier & Total \\
\hline Lack of Computer skills & $15(50 \%)$ & $10(33.33 \%)$ & $5(16.67 \%)$ & 30 \\
\hline $\begin{array}{c}\text { Lack of uniform industry } \\
\text { standards }\end{array}$ & $9(30 \%)$ & $16(53.3 \%)$ & $5(16.67 \%)$ & 30 \\
\hline $\begin{array}{c}\text { Poor administrative } \\
\text { policy }\end{array}$ & $10(33.33 \%)$ & $18(60 \%)$ & $2(6.66 \%)$ & 30 \\
\hline Inadequate Training & $8(26.67 \%)$ & $12(40 \%)$ & $10(33.33 \%)$ & \\
\hline
\end{tabular}

Table 7:- shows respondents' barriers to the implementation of Electronic Health Records (EHR)

The table above shows that respondents' perception of barriers to implementation of Electronic Health Records, It reveals that large percentage $(60 \%)$ of the respondents perceive poor administrative policy as a minor barrier to implementation of Electronic Health records. Equally, about $16.67 \%$ and $33.33 \%$ of the respondents perceived that lack of computer skills and inadequate training are major barriers to Electronic Health records in Tertiary Health Institution. However majority of the respondents $(50 \%)$ perceived computer skills not a barrier which depicts that majority of Health Management Professionals in the institution are computer literate.

\section{DISCUSSION}

The study assess the perception of the Health Information management professionals on the importance of computer application in Health information system, however research questions were raised to achieve the target objectives. The respondents were asked how critical is Electronic Health Record (EHR) needed in meeting their organization goals as Health Information management Professional, larger percentage of the respondents opined that Electronic Health Record is critically needed for Clinical quality, Patience service and Operation service. This position agrees with Chaudhry et.al (2006) [14] who reported that technology has been adjudged by both health care experts and health care consumers as having critical roles to play in the transformation of healthcare.

Equally, $80 \%$ of the respondents agree that computer is very important in Health Information Management, this equally upholds the findings of Ibrahim et.al 2015 [15] who reported that virtually all the participants across healthcare professions indicated that computer application is very important in management of health information to improve medical care quality. Also, Strivastava et al. in 2014 [16] stated that studies among resident doctors, dentist, medical laboratory scientists and students revealed that they have good knowledge about the importance of computer application in health information. Similarly respondents who are Health Information Management Professionals rated their performance high which agrees with Ibrahim et al 2015 [15] who stated that health care professionals were advance in the use of electronic mail, internet, use of word processor i.e. Microsoft Word in which Health Information Management Professionals are leading. This equally supported the findings of this study in which higher percentage of the respondents find computer application easy and satisfying. However, in contrast to most literature, acquisition of computer skills is perceived as a barrier in achieving effective Electronic Heath Record in the study area.

\section{CONCLUSION}

The Electronic Health Records (HER) provides the essential infrastructure required to enable the adoption and effective use of new healthcare modalities such as integrated care, evidenced-based medicine, computer-based decision support, care planning and outcomes analysis. Therefore, the benefits that support implementation of an EHR are clear, there are still barriers too, therefore the concept is still not accepted. However, this could also be said of almost every other area of positive change and improvement within healthcare system. There must be more involvement by the government and the private sector to make changes where possible to instigate, motivate, and provide incentives to accelerate the development of solutions to overcome the barriers. There are obviously advantages and disadvantages to both the paper medical record and the Electronic Health Records (EHR).

The study therefore reveals that knowledge and level of adoption of computer science among Health information Management Professionals in the institution was considerably good, however, rate of technology knowledge and adaptation need to be improved. This may be due to lack of structured training and computer accessibility. The institution must provide computer access to staff. Also by reinforcement of educational infrastructures, provide the possibility of increasing knowledge of health information technology among Health Information Professionals.

\section{RECOMMENDATIONS}

Education on Electronic Health Information (EHR)is required for training of staff to allow them to know the nature of EHR itself

$>$ Computerization should only be made a priority as it supports the overall objectives of the Health institution

$>$ There must be more involvement by the government and the private sector to make changes possible to instigate, motivate, and provide incentives to accelerate the development of solutions to overcome the barriers of computerization of Health information

\section{ACKNOWLEDGEMENT}

Appreciation goes to all who contributed to the success of this article. 


\section{REFERENCES}

[1]. J. Murray. , (2014) . Cloud network architecture and ICT. Information and communication technology. Available at: http://itknowledgeexchange.techtarget.com/modernnetworkarchitecture/ cloud-network-architectureand-ict/. Accessed on: December 19

[2]. Virki T. (2008) Reuters: Computers in use pass 1 billion mark: Gartner. c. [Last accessed on 2013 Oct 28]. Available from: http://www.reuters.com/article/technologynews/ idus

[3]. Friede A, O'Carroll PW. (1996). CDC and ATSDR electronic information resources for health officers. J Public Health Manage Pract. 2:10-24

[4]. Friede A, Blum HL, McDonald M. (1995). Public health informatics: How information-age technology can strengthen public health. Annu Rev Public Health. 16:239-52

[5]. Wallace R, Doebbeling B. (2010). Investigation of an epidemic. In: Maxcy RL, editor. Public Health and Preventive Medicine. 15th ed. New York: McGraw Hills Companies;. pp. 10-24

[6]. Greenes RA, Shortliffe EH. (1990) Medical informatics: An emerging academic discipline and institutional 20. [PubMed] [Google Scholar]

[7]. P. J. Cruickshank. Computer in medicine: patients' attitudes. Journal of Royal College of General Practitioners. 1984; 34: $77-80$.

[8]. J. W. Fairley. Computers in medicine. Journal of Royal Society of Medicine.1991; 84: 566 567.

[9]. Ndunagu, JN. Website Design \& Programming. National Open University of Nigeria (Course Material).2010; pp21.

[10]. History of the Internet. Available at: en.wikipedia.org/wiki/History_of_the_Internet.htm. Accessedon: January 10th 2013

[11]. Ehrenfeld JM, Cannesson M. Monitoring Technologies in Acute Care Environments: A Comprehensive Guide to Patient Monitoring Technology: Springer; 2013

[12]. Ahlan AR, Ahmad BIe. User Acceptance of Health Information Technology (HIT) in Developing Countries: A Conceptual Model. Procedia Technology. 2014;16:1287-96.

[13]. Anderson N. 2009. Implementation Guide for CDA Release 2 : Quality Reporting Document Architecture (QRDA), Release 1, April 16, 2009, HL7 International http://www.h17.org/documentcenter/ballots/2008s ep/downloads/CDAR2 QRDA RI DSTU 2009APR.zips

[14]. B. Chaudhry, J. Wang, S. Wu, et al. Systematic review: impact of health information technology on quality, efficiency and costs of medical care. Ann Intern Med. 2006; 144:742-752.
[15]. Ibrahim Taiwo Adeleke, Adejoke Abiola Salami, Moses Achinbee, Tony Chucks Anamah, Ibrahim Babaminin Zakari, Muhammad Hassan Wasagi. ICT knowledge, Utilization and Perception among Healthcare Providers at National Hospital Abuja, Nigeria. American Journal of Health Research. Special Issue: Health Information Technology in Developing Nations: Challenges and Prospects Health Information Technology.

Vol. 3, No. 1-1, 2015, pp. 47-53.

[16]. SrivaSTava TK, Waghmare LS, Jagzape AT, Rawekar AT, Quazi NZ, Mishra VP. Role of information communication technology in higher education: Learners perspective in rural medical schools. Journal of clinical and diagnostic research: JCDR. 2014;8(6):XC01. 